Research

\title{
The effect of intraperitoneal administration of BromAc on blood parameters: phase 1 study
}

\author{
Kevin Ke $\mathrm{Ke}^{1,2} \cdot$ Krishna Pillai $^{1,2} \cdot$ Ahmed H. Mekkawy ${ }^{1,2} \cdot$ Javed Akhter $^{1,2} \cdot$ Samina Badar $^{1,3} \cdot$ Sarah J. Valle $^{1,2}$. \\ David L. Morris ${ }^{1,2,3}$
}

Received: 9 May 2021 / Accepted: 19 July 2021

Published online: 16 August 2021

(c) The Author(s) 2021 OPEN

\begin{abstract}
Intraperitoneal administration of BromAc (bromelain + acetylcysteine) is currently undergoing a phase 1 clinical trial for pseudomyxoma peritonei at our institution. This study reports on analysis of routine blood parameters before and after treatment for a series of 25 patients in this trial. Blood parameters assessed included full blood count, electrolytes, urea, and creatinine, liver function tests, coagulation studies, as well as inflammatory markers (CRP). Certain parameters such as CRP, and white cell count, were significantly elevated after treatment whilst serum albumin level was reduced indicating an inflammatory reaction. However, liver enzymes, coagulation studies, and other parameters were not affected. Therefore, there are no additional safety signals evident upon analysis of routine blood parameter testing.
\end{abstract}

Keywords Pseudomyxoma peritonei PMP $\cdot$ Bromelain · Acetylcysteine $\cdot$ BromAc $^{\circledR} \cdot$ Blood

\section{Introduction}

Pseudomyxoma peritonei (PMP) is a syndrome characterised by mucinous ascites, secreted by tumours of primarily appendix, ovary, or of bowel origin. It has an estimated incidence of 0.3 per 100,000 people, and a prevalence of 2 in 100,000 [1]. Current standard of care treatment involves cytoreductive surgery (CRS) with heated intraperitoneal chemotherapy (HIPEC), which has been reported to offer prolonged survival even when extensive disease is present. A multicentre registry incorporating data from 1548 patients with PMP undergoing CRS + HIPEC demonstrated 5-year survival of $58 \%$ [2]. However, this is a major procedure, with $33 \%$ of patients experiencing grade 3-5 morbidity [2]. Furthermore, treated patients may require repeat procedures owing to tumour recurrence $[3,4]$. In a multicentre database of 1411 CRS + HIPEC procedures performed over two decades, it was reported that the rate of early recurrence in the first 5 years post-procedure was $25 \%$. However, on closer inspection, the true figure is much higher, as it was reported that of the 262 patients followed up for over 10 years, 192 patients (75\%) experienced a recurrence in the first 5 years, and only 33 patients (13\%) had no recurrence after 10 years [5]. Repeat surgeries are more surgically complex, confer increased morbidity and can usually only be performed 2 or 3 times before patients are inoperable [5, 6]. Chemotherapy is largely ineffective due to tumor cells being engulfed by mucin, forming a protective barrier preventing chemotherapy penetration [7]. Clearly there is a need for improved therapies.

David L. Morris, david.morris@unsw.edu.au| 'Department of Surgery, St. George Hospital, Kogarah, NSW 2217, Australia. ${ }^{2}$ Mucpharm Pty Ltd, Kogarah, NSW, 2217, Australia. ${ }^{3}$ St George \& Sutherland Clinical School, University of New South Wales, Sydney, NSW 2217, Australia.

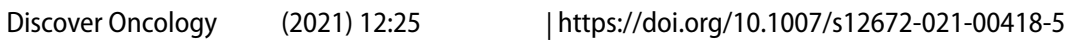


A therapy currently undergoing development at our institution is bromelain in combination with acetylcysteine (BromAc) for intraperitoneal therapy. Bromelain is derived from the stem of pineapple (Ananas comosus), containing a mixture of enzymes such as proteases, peroxidases, cellulases, glucosidases, esterases, glucosidases, etc. along with glycoproteins [8]. Acetylcysteine is an antioxidant commonly used for treating paracetamol toxicity [9] and as a mucolytic for treating cystic fibrosis [10] and chronic obstructive pulmonary disease (COPD) [11]. Bromelain is known to cleave peptide and glycosidic bonds while acetylcysteine reduces inter mucin disulphide linkages, resulting in the disintegration and solubilization of mucin when used in combination [12]. The safety and early feasibility of BromAc has been confirmed recently in a clinical trial where over 20 patients were treated successfully [13], although there was an elevation of C-reactive protein (CRP) in all patients indicative of inflammatory reaction that may been caused locally due to the proteolytic action of bromelain on tissues and blood vessels lining the peritoneal cavity. Further, since BromAc was delivered intraperitoneally to a highly vascular surface, it is envisaged that BromAc will gain entry systemically and hence may affect other organ systems. Therefore, we examined the levels of certain blood biomarkers, at baseline and post-treatment, to assess the effect of BromAc on organ systems.

\section{Methods}

\subsection{General}

The study involved patients with mucinous peritoneal tumour including PMP that were deemed inoperable. All patients were presented to a multi-disciplinary team (MDT) for suitability of trial entry and educated about the procedure prior to consenting. A pre-treatment computed tomography (CT) scan for assessment of the tumour as well as calculation of the size and the volume of tumour to be treated were required for discussion at the MDT meeting. Baseline blood tests including full blood count, liver function, renal function, C-reactive protein (CRP), fibrinogen and coagulation tests were also required. A Patient Information Booklet was given to the subjects for review and follow-up with any additional questions answered prior to consenting to treatment. Following completion of investigations and suitability for entry, if the patient was willing to provide informed consent, the form was signed. Educational and additional appointments with supporting services and further review with other disciplines were requested as required. The patient was provided with a signed copy of the patient information booklet, a fully executed copy of consent form and day of procedure instructions. A pre-treatment baseline symptom questionnaire and quality of life forms were completed.

On the day of the procedure, the patient was fasted for $6 \mathrm{~h}$ and administered oral antihistamine (Loratadine $10 \mathrm{mg}$ ) before treatment. Drug was administered directly into tumour or peritoneal cavity via drain and allowed to dwell for $24 \mathrm{~h}$. Then, the tumour was drained, and repeat treatment was considered on subsequent days. Injection was performed under radiological guidance by an interventional radiologist through percutaneously inserted drain, remaining in situ for the treatment period. Aspiration and drainage were through this drain, and dosage was dependent on the calculated tumour dimensions and volume. Briefly, Bromelain (MucPharm Pty Ltd, Australia; Challenge Bioproducts Co Ltd, Taiwan) 20-45 mg (intra-tumoral injections) or 45-60 mg (intra-peritoneal injections) and Acetylcysteine (Acetylcysteine-Link, Link Pharma, Australia) 1-1.5 g (intra-tumoral injections) or $2 \mathrm{~g}$ (intra-peritoneal injections) were reconstituted and administered in $5 \%$ glucose through a sterile Millex $0.22 \mu \mathrm{m}$ syringe filter. The injected volume injected, as feasible, was corresponding to $20 \%$ of the target tumour volume (intra-tumoral) or $500 \mathrm{~mL}$ (intra-peritoneal). The maximum daily dose was $60 \mathrm{mg}$ Bromelain and $2 \mathrm{~g}$ Acetylcysteine. Further details regarding study design can be found in the referenced paper [13]. The trial is registered at Clinicaltrials.gov (NCT03976973) and anzctr.org.au (ACTRN12617001612303). Ethics approval for this study was provided by Bellberry Ltd (2017-07-561) and patients that did not meet criteria including retreatments were conducted via compassionate access using the same protocol and reporting requirements.

A total of 25 patients were treated with BromAc intraperitoneally from February 2018 to May 2020. There were in total 42 treatment periods recorded, with a treatment period defined as a set of treatments which were not separated by an interval of time longer than 7 days. Of these 42 periods, 32 were able to be analysed as blood parameters were recorded at suitable time points, from 20 different patients. Pre-treatment blood tests were taken any time from the period of 2 weeks prior to initiation of treatment, up until the day of treatment. Post-treatment blood tests were the first set of blood tests taken following the last treatment, taken within 1 week of their last dose. 


\subsection{Analysis and quantification of routine blood biomarkers}

All blood samples collected were analysed following standard laboratory protocol by the clinical pathology service of St George Hospital, Sydney (SEALS pathology).

\subsection{Blood bromelain quantification}

Bromelain concentrations in plasma of patients were quantified using ELISA developed in house using pre coated 96 well plates with mouse monoclonal anti bromelain antibody at a dilution of $1 / 500$ in coating buffer at $37^{\circ} \mathrm{C} / 24 \mathrm{~h}$. The plates were then washed and treated to different concentrations ranging from 20 to $600 \mathrm{ng} / \mathrm{mL}$ of bromelain, incubated at $37^{\circ} \mathrm{C} / 2 \mathrm{~h}$, washed with washing buffer and then treated with HRP labelled anti mouse antibody after which substrate was added following standard procedure [14].

\subsection{Statistical analysis}

Results from the measurement of blood biomarkers were analysed using GraphPad Prism 9, and the statistical test used to assess for significance was the Wilcoxon matched-pairs signed rank test. $P$-values under 0.05 were judged to be significant.

\section{Results}

\subsection{Patient and treatment parameters}

The mean age of patients assessed was 64 , with a range from 38 to 82 years old. Patients assessed received a mean dosage of $124 \mathrm{mg}$ of bromelain, and $4.9 \mathrm{~g}$ of acetylcysteine per treatment period. Each treatment period consisted of a mean of 3.8 separate drug administrations over different days.

Additional subgroup analyses were performed, dividing the 32 treatment periods into 16 low dose periods (cumulative bromelain dose $<100 \mathrm{mg}$ ) and 16 high dose periods (cumulative bromelain $>100 \mathrm{mg}$ ). The low dose group received a mean of $64 \mathrm{mg}$ of bromelain and $2.7 \mathrm{~g}$ of acetylcysteine. The high dose group received a mean of $183 \mathrm{mg}$ of bromelain, and $7.2 \mathrm{~g}$ of acetylcysteine, approximately 3-times the dosage of the low dose group. Female patients as well as older patients were more likely to be treated with lower dosages compared to male patients and younger patients (Table 1). Dosing was calculated based on tumour volume. Patients were assessed after each injection for tolerability and response, and treatments were continued it was determined to be clinically beneficial and tolerable. The lowest dosage treatment period assessed consisted of $38 \mathrm{mg}$ of bromelain and $1.9 \mathrm{~g}$ of acetylcysteine, while the highest dosage treatment period assessed was $325 \mathrm{mg}$ of bromelain and $14 \mathrm{~g}$ of acetylcysteine.

\subsection{Blood biomarkers}

Blood biomarker analysis and statistical evaluation of the whole treatment group indicated that various biomarkers were either impacted by treatment, evident when comparing their post-treatment to baseline blood parameter measurements (Table 2). In particular, CRP was substantially elevated from mean value of 43 to $142 \mathrm{mg} / \mathrm{L}$ post-treatment $(p<0.001)$. Other

Table 1 Patient parameters

\begin{tabular}{llll}
\hline & Low doses & High doses & All doses \\
\hline Total treatment periods $(\mathrm{n})$ & 16 & 16 & 32 \\
Mean age of all patients (years) & 67 & 61 & 64 \\
$\%$ Female & 57 & 38 & 47 \\
$\%$ Low dose (<100 mg bromelain) & 100 & 0 & 50 \\
$\%$ High dose (> 100 mg bromelain) & 0 & 100 & 50 \\
Mean dosage of bromelain (mg) & 65 & 183 & 124 \\
Mean dosage of acetylcysteine $(\mathrm{g})$ & 2.7 & 7.2 & 4.9 \\
\hline
\end{tabular}


Table 2 Blood biomarkers in all BromAc treated patients

\begin{tabular}{|c|c|c|c|c|c|}
\hline Parameter & Units & Baseline (mean $\pm S D$ ) & $\begin{array}{l}\text { Post-treatment } \\
(\text { mean } \pm \text { SD) }\end{array}$ & $p$-value & $\mathrm{n}$ \\
\hline Sodium & $\mathrm{mmol} / \mathrm{L}$ & $140.03 \pm 2.89$ & $138.88 \pm 3.19$ & 0.07 & 32 \\
\hline Potassium & $\mathrm{mmol} / \mathrm{L}$ & $4.42 \pm 0.55$ & $4.41 \pm 0.56$ & 0.93 & 32 \\
\hline Chloride & $\mathrm{mmol} / \mathrm{L}$ & $101.42 \pm 3.34$ & $99.38 \pm 3.78$ & 0.002 & 31 \\
\hline Bicarbonate & $\mathrm{mmol} / \mathrm{L}$ & $31.31 \pm 37.37$ & $26.22 \pm 2.61$ & 0.6 & 31 \\
\hline Urea & $\mathrm{mmol} / \mathrm{L}$ & $5.9 \pm 2.81$ & $6.08 \pm 3.79$ & 0.63 & 31 \\
\hline Creatinine & $\mu \mathrm{mol} / \mathrm{L}$ & $77.16 \pm 21.69$ & $81.87 \pm 25.61$ & 0.36 & 31 \\
\hline Total bilirubin & $\mu \mathrm{mol} / \mathrm{L}$ & $8.34 \pm 5.08$ & $12.22 \pm 13.98$ & 0.31 & 32 \\
\hline Total protein & $g / L$ & $68.45 \pm 9.01$ & $65.94 \pm 6.92$ & 0.1 & 31 \\
\hline Albumin & $g / L$ & $30.25 \pm 6.99$ & $26.25 \pm 5.85$ & 0.01 & 32 \\
\hline CRP & $\mathrm{mg} / \mathrm{L}$ & $43.07 \pm 56.58$ & $142.42 \pm 109.76$ & $<0.001$ & 28 \\
\hline ALP & $\mathrm{U} / \mathrm{L}$ & $161.88 \pm 159.6$ & $176.19 \pm 152.56$ & 0.8 & 32 \\
\hline GGT & $U / L$ & $104.97 \pm 210.06$ & $112.75 \pm 183.86$ & 0.47 & 31 \\
\hline ALT & $\mathrm{U} / \mathrm{L}$ & $33.34 \pm 28.73$ & $40.44 \pm 61.27$ & 0.93 & 32 \\
\hline AST & $\mathrm{U} / \mathrm{L}$ & $32.55 \pm 27.68$ & $36.19 \pm 51.91$ & 0.51 & 30 \\
\hline Haemoglobin & $10^{9} / \mathrm{L}$ & $112.97 \pm 24.91$ & $112.09 \pm 20.86$ & 0.67 & 32 \\
\hline WCC & $10^{9} / \mathrm{L}$ & $9.06 \pm 3.86$ & $11.48 \pm 3.36$ & 0.001 & 32 \\
\hline Neutrophils & $10^{9} / \mathrm{L}$ & $5.9 \pm 3.59$ & $8.31 \pm 3.15$ & 0.002 & 31 \\
\hline Lymphocytes & $10^{9} / \mathrm{L}$ & $2.03 \pm 1.02$ & $1.62 \pm 0.99$ & 0.01 & 31 \\
\hline Monocytes & $10^{9} / \mathrm{L}$ & $0.86 \pm 0.32$ & $1.19 \pm 0.5$ & 0.002 & 31 \\
\hline Eosinophils & $10^{9} / \mathrm{L}$ & $0.23 \pm 0.21$ & $0.22 \pm 0.17$ & 0.73 & 31 \\
\hline Basophils & $10^{9} / \mathrm{L}$ & $0.04 \pm 0.03$ & $0.03 \pm 0.02$ & 0.03 & 31 \\
\hline Platelets & $10^{9} / \mathrm{L}$ & $426.28 \pm 172.81$ & $492.48 \pm 238.39$ & 0.2 & 32 \\
\hline INR & INR & $1.24 \pm 0.36$ & $1.27 \pm 0.45$ & 0.73 & 28 \\
\hline APTT & $s$ & $34.76 \pm 14.32$ & $34.1 \pm 9.39$ & 0.6 & 29 \\
\hline
\end{tabular}

ALP alkaline phosphatase, ALT alanine transaminase, APTT activated partial thromboplastin time, AST aspartate transaminase, CRP C-reactive protein, GGT gamma glutamyl transpeptidase, INR international normalized ratio, SD standard deviation, WCC white cell count

biomarkers that were enhanced are white blood cells (WCC), neutrophils and monocytes. Albumin and lymphocytes were on the other hand depressed (Table 2, Figs. 1, 2, and 3).

Both the low dosage and high dosage groups demonstrated sharp increases in CRP, and derangements to various white blood cell types (neutrophils, lymphocytes, monocytes). Both groups demonstrated numerical decreases in serum albumin concentration, although these were not statistically significant. There were no additional signals evident in any other blood parameters when conducting the subgroup analysis (Tables 3, 4, Figs. 1, 2, 3).

Of note, liver enzymes were not impacted by BromAc treatment in a statistically significant manner as previously thought, although numerically, the mean values of ALP, GGT, ALT and AST were slightly higher post-treatment (Tables 2, 3, 4). Platelets were not significantly impacted by treatment, nor were INR or APTT values (Table 5). There was also no increase in creatinine observed. In terms of serum electrolytes, there was a slight mean reduction of sodium concentration from 140 to $139 \mathrm{mmol} / \mathrm{L}$, as well as a reduction in serum chloride concentrations from 101 to $99.5 \mathrm{mmol} / \mathrm{L}(p=0.002)$ although these concentrations remained well within the normal reference ranges and are likely clinically irrelevant.

BromAc delivered by intra-tumoral injection (IT) at $1.5 \mathrm{mg} / \mathrm{mL}$ resulted in a blood concentration of $110 \mathrm{ng} / \mathrm{mL}$ at $3 \mathrm{~h}$, whilst intraperitoneal (IP) delivery at a concentration of $0.75 \mathrm{mg} / \mathrm{mL}$ resulted in blood concentration of $440 \mathrm{ng} / \mathrm{mL}$ at $2 \mathrm{~h}$ followed by a decline to $350 \mathrm{ng} / \mathrm{mL}$ at $5 \mathrm{~h}$. Intraperitoneal delivery $(0.75 \mathrm{mg} / \mathrm{mL})$ may result in a higher absorption through peritoneal membrane as opposed to IT delivery at $1.5 \mathrm{mg} / \mathrm{mL}$ (Table 6). 
Fig. 1 Shows the effect of BromAc treatment on blood level of sodium, potassium, chloride, bicarbonate, urea, bilirubin, total protein and globulin, before and after treatment in all patients. Sodium, chloride and total protein were slightly depressed post-treatment

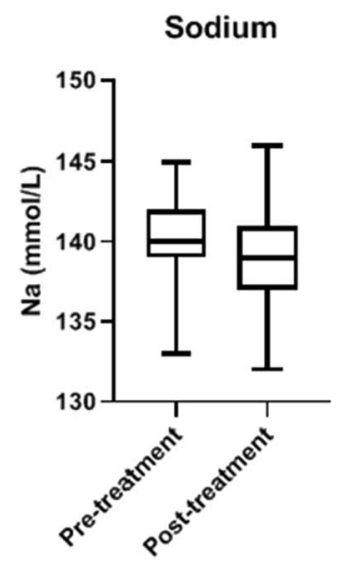

Bicarbonate

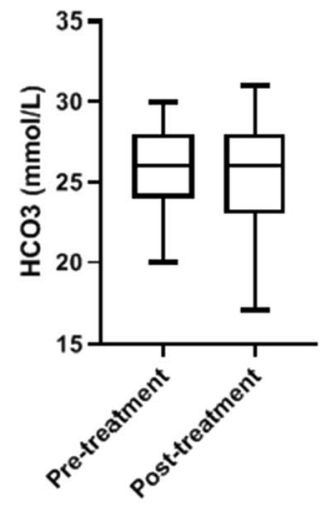

Total Protein

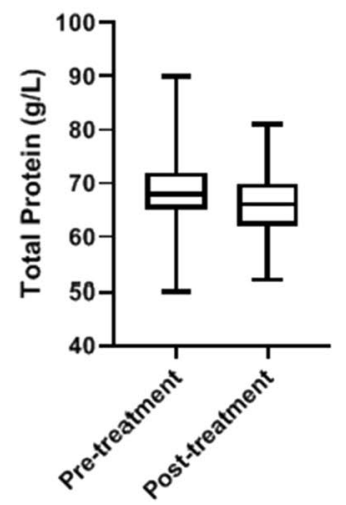

Potassium

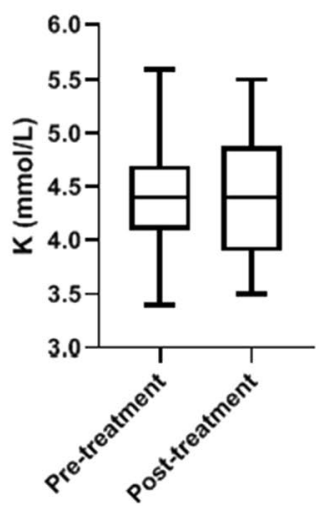

Urea

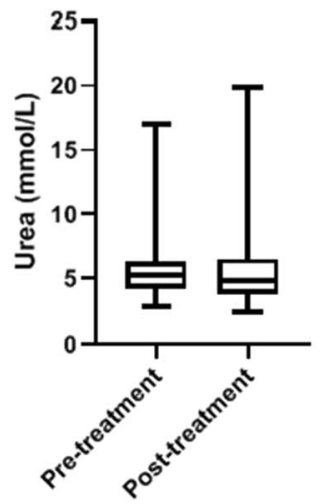

Globulin

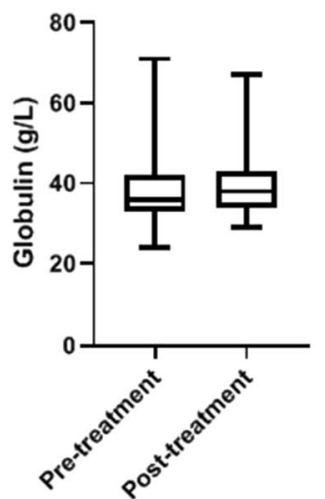

Chloride

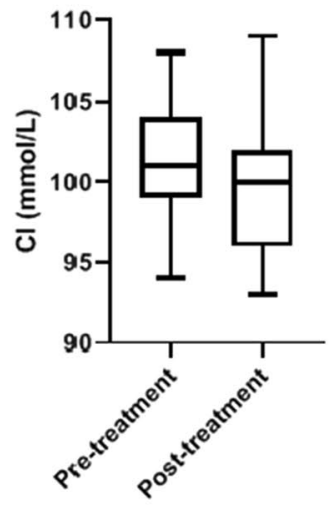

Bilirubin

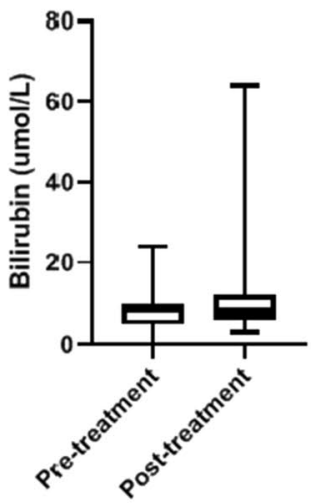

\section{Discussion}

Importantly, the present investigation reveals no evidence of liver toxicity, kidney toxicity, or derangement to the coagulation profile of patients receiving the specified range of BromAc doses. In the initial publication of the clinical trial, it was speculated that drug administration was causing instances of raised liver enzyme serum concentrations [13]. However, this investigation raises the possibility that those reported cases may have purely represented statistically random fluctuations unrelated to BromAc administration. This is because AST, ALT, GGT, as well as ALP were not affected in a statistically significant manner in both the low and high dosage groups. Furthermore, although bromelain is known to have anticoagulative action owing to its biochemical interaction with the coagulation cascade 
Fig. 2 Shows the effect of BromAc treatment on blood level of haemoglobin, neutrophils, lymphocytes, monocytes, eosinophils, basophils, platelets, INR, and APTT, before and after treatment in all patients. INR international normalisation ratio, APTT activated partial thromboplastin time (s). Neutrophils, monocytes and eosinophils were slightly increased posttreatment whilst lymphocytes and basophils were slightly depressed
Haemoglobin

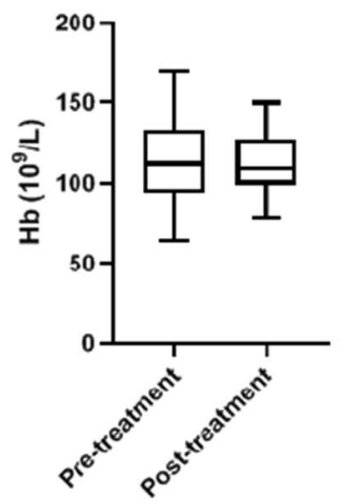

Monocytes

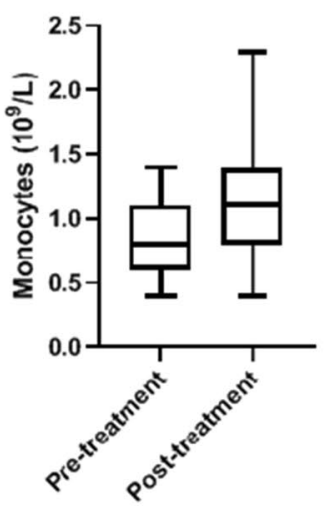

Platelets

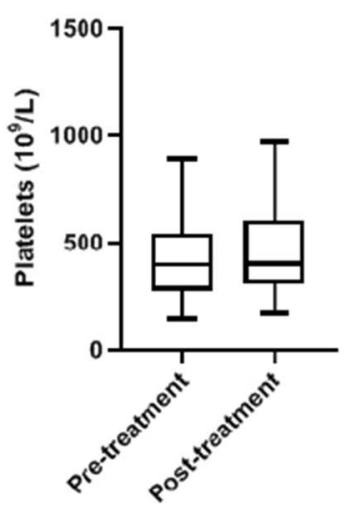

Neutrophils

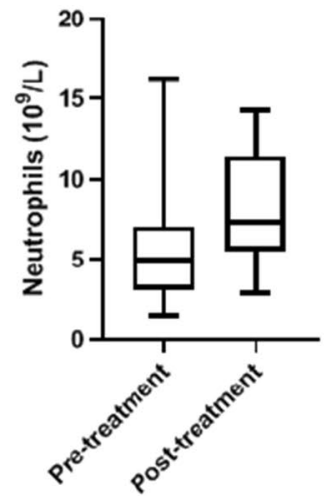

Eosinophils

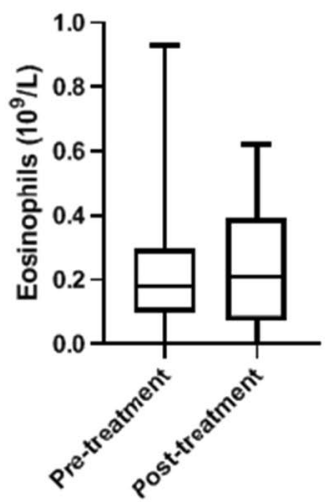

INR

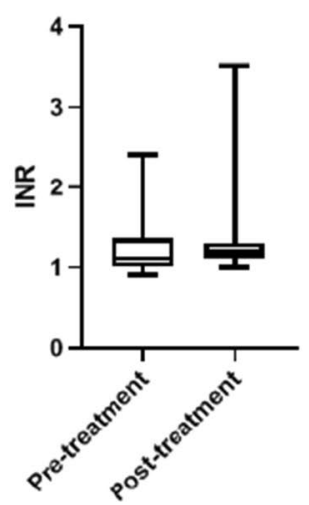

Lymphocytes

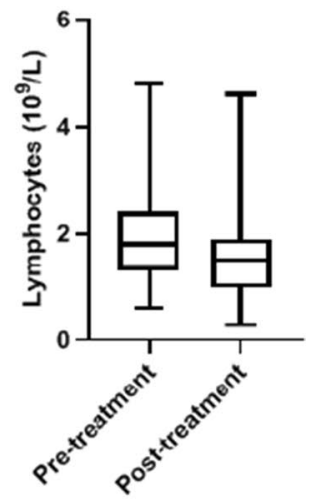

Basophils

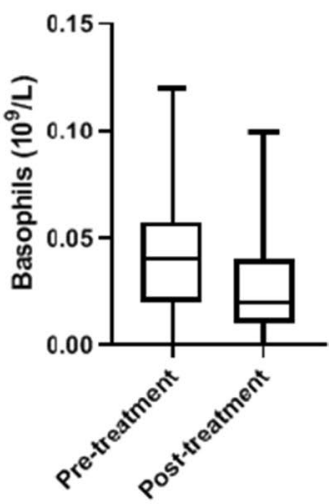

APTT

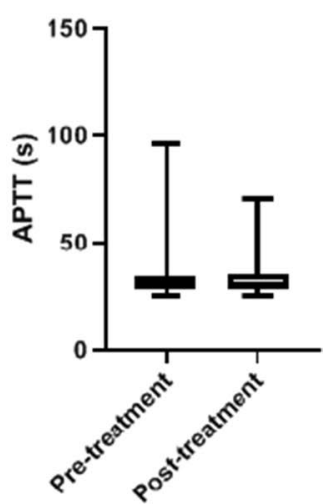

[15], the dosage delivered in this investigation seems to have no effect upon coagulation related parameters. Therefore, this investigation forms an important part of our understanding of BromAc's safety profile, supporting the case for further development of the drug as a novel mucolytic agent when given through the intraperitoneal or intratumoral route.

Analysis of the whole treatment group indicated that acute phase reactants such as CRP, white blood cell count (WCC), neutrophils and monocytes were increased in a statistically significant manner consistent with an acute phase reaction [16]. These changes were observed in both high dose and low dose subgroups consistently. Most noticeably, CRP was increased over twofold from the patients' already elevated baseline concentrations. Other biomarkers were also enhanced significantly indicating inflammation, possibly at the site of BromAc delivery. The monocytes to lymphocytes ratio (MLR), neutrophil to lymphocytes ratio (NLR) and platelets to lymphocytes ratio (PLR) were all increased in a 
Fig. 3 Shows the effect of BromAc treatment on blood level of CRP (C-reactive protein), albumin, white cell count, creatinine, alkaline phosphatase, gamma glutamyl transpeptidase, alanine aminotransferase, aspartate aminotransferase and INR before and after treatment in all patients. CRP and white cell count were increased whilst albumin and creatinine were slightly depressed posttreatment
CRP

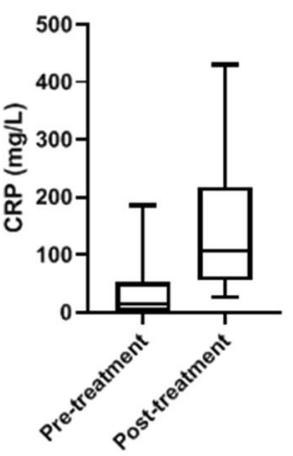

Creatinine

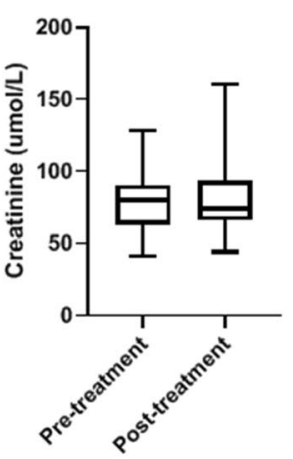

Alanine Aminotransferase

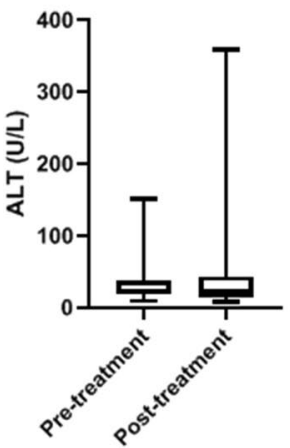

Albumin

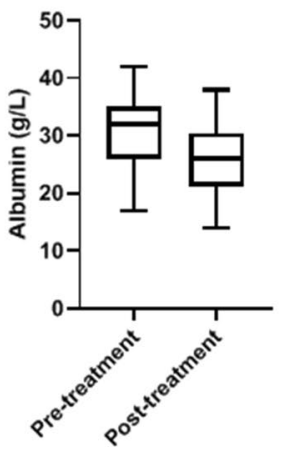

Alkaline Phosphatase

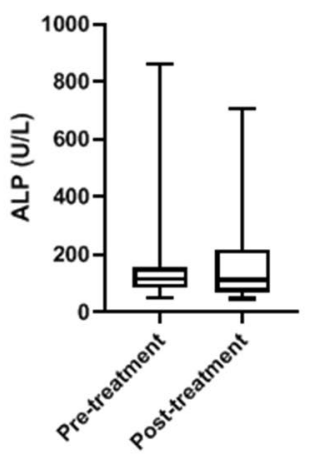

Aspartate Aminotransferase

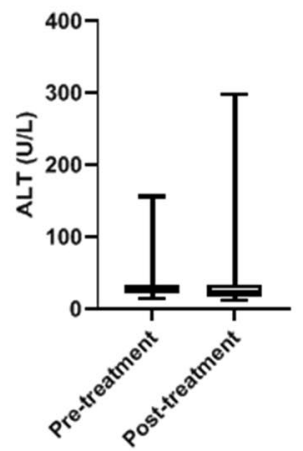

White Cell Count

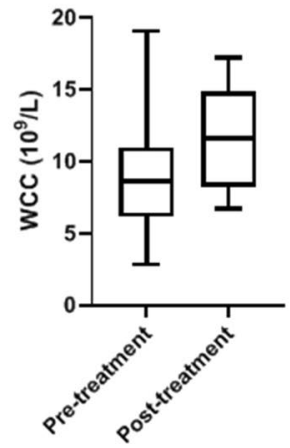

Gamma Glutamyl Transpeptidase

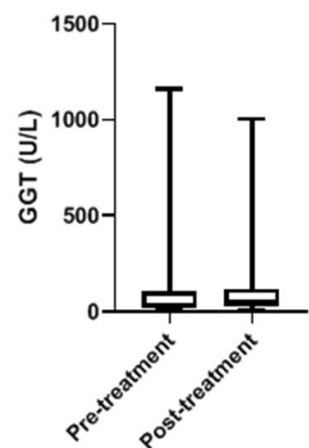

INR

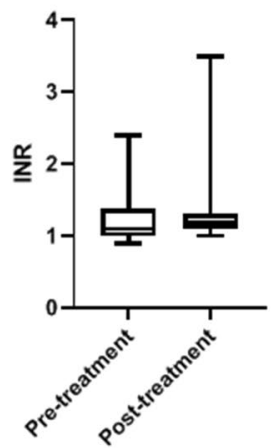

statistically significant manner indicating inflammation $[17,18]$. The presence of high concentrations of acetylcysteine may also disrupt cellular surfaces, as it is well known that acetylcysteine enhances the absorption of certain antibiotics mainly through its reductive action on disulphide linkages found in cellular membrane proteins. Although bromelain is known for its anti-inflammatory properties [19], in the present investigation it has evoked an inflammatory reaction. The administration of intraperitoneal bromelain to mice has previously demonstrated disruption of peritoneal surfaces with mild bleeding and clotting reported [20,21]. It is important to note that baseline values of neutrophils and platelets were higher in our patient population compared to the normal population, while lymphocytes were lower (Table 3) [22, 23]. This is likely due to a background level of chronic inflammation caused by late-stage cancer.

Albumin was consistently depressed in the present study, consistent with the presence of inflammation as it is a negative acute phase reactant [24]. Albumins are composed of different amino acids that are linked together by peptide bonds [25] whilst their molecular geometry is dictated by the disulphide bonds [26], hence they are highly prone to chemical reactivity by BromAc. This partial disintegration of albumin may contribute to the lower levels of albumin measured in blood, although this requires clarification in future studies. On the other hand, the generation of reactive radicals at the 
Table 3 Blood biomarkers in low dosage patients (<100 mg bromelain)

\begin{tabular}{|c|c|c|c|c|c|}
\hline Parameter & Units & Baseline (mean $\pm S D$ ) & $\begin{array}{l}\text { Post-treatment } \\
(\text { mean } \pm \text { SD) }\end{array}$ & $p$-value & $\mathrm{n}$ \\
\hline Sodium & $\mathrm{mmol} / \mathrm{L}$ & $139.69 \pm 3.03$ & $138.5 \pm 3.1$ & 0.32 & 16 \\
\hline Potassium & $\mathrm{mmol} / \mathrm{L}$ & $4.42 \pm 0.52$ & $4.35 \pm 0.61$ & 0.81 & 16 \\
\hline Chloride & $\mathrm{mmol} / \mathrm{L}$ & $100.94 \pm 3.7$ & $99.25 \pm 3.19$ & 0.12 & 16 \\
\hline Bicarbonate & $\mathrm{mmol} / \mathrm{L}$ & $25.56 \pm 3.5$ & $25.56 \pm 2.9$ & 0.61 & 16 \\
\hline Urea & $\mathrm{mmol} / \mathrm{L}$ & $5.83 \pm 3.35$ & $6.18 \pm 4.73$ & 0.99 & 16 \\
\hline Creatinine & $\mu \mathrm{mol} / \mathrm{L}$ & $78.06 \pm 20.52$ & $82.81 \pm 31.23$ & 0.83 & 16 \\
\hline Total bilirubin & $\mu \mathrm{mol} / \mathrm{L}$ & $8.69 \pm 5.69$ & $13.13 \pm 14.26$ & 0.24 & 16 \\
\hline Total protein & $g / L$ & $68.56 \pm 7.13$ & $66.13 \pm 6.9$ & 0.26 & 16 \\
\hline Albumin & $\mathrm{g} / \mathrm{L}$ & $31.19 \pm 6.81$ & $28.19 \pm 5.54$ & 0.1 & 16 \\
\hline CRP & $\mathrm{mg} / \mathrm{L}$ & $37.6 \pm 61.99$ & $138.69 \pm 118.76$ & $<0.001$ & 15 \\
\hline ALP & $U / L$ & $169.13 \pm 198.13$ & $175.81 \pm 184.16$ & 0.75 & 16 \\
\hline GGT & $U / L$ & $134.38 \pm 284.65$ & $133.88 \pm 252.5$ & 0.65 & 16 \\
\hline ALT & $\mathrm{U} / \mathrm{L}$ & $41.69 \pm 38.34$ & $53.69 \pm 84.1$ & 0.89 & 16 \\
\hline AST & $U / L$ & $40.31 \pm 36.94$ & $43.75 \pm 68.77$ & 0.67 & 16 \\
\hline Haemoglobin & $10^{9} / \mathrm{L}$ & $118.75 \pm 21.34$ & $118.56 \pm 19.5$ & 0.95 & 16 \\
\hline WCC & $10^{9} / \mathrm{L}$ & $8.27 \pm 3.66$ & $11.45 \pm 3.64$ & 0.02 & 16 \\
\hline Neutrophils & $10^{9} / \mathrm{L}$ & $4.94 \pm 3.33$ & $8.19 \pm 3.67$ & 0.02 & 16 \\
\hline Lymphocytes & $10^{9} / \mathrm{L}$ & $2.19 \pm 1.1$ & $1.74 \pm 1.19$ & 0.05 & 16 \\
\hline Monocytes & $10^{9} / \mathrm{L}$ & $0.85 \pm 0.3$ & $1.26 \pm 0.44$ & 0.03 & 16 \\
\hline Eosinophils & $10^{9} / \mathrm{L}$ & $0.27 \pm 0.24$ & $0.24 \pm 0.15$ & 0.71 & 16 \\
\hline Basophils & $10^{9} / \mathrm{L}$ & $0.05 \pm 0.03$ & $0.03 \pm 0.03$ & 0.03 & 16 \\
\hline Platelets & $10^{9} / \mathrm{L}$ & $379.19 \pm 146.2$ & $390.44 \pm 161.26$ & 0.56 & 16 \\
\hline INR & INR & $1.23 \pm 0.37$ & $1.34 \pm 0.6$ & 0.58 & 15 \\
\hline APTT & $s$ & $31.93 \pm 5.7$ & $32.8 \pm 6.52$ & 0.53 & 15 \\
\hline
\end{tabular}

ALP alkaline phosphatase, ALT alanine transaminase, APTT activated partial thromboplastin time, AST aspartate transaminase, CRP C-reactive protein, GGT gamma glutamyl transpeptidase, INR international normalized ratio, SD standard deviation, WCC white cell count

site of inflammation may attract albumin since it is an antioxidant that is capable of quenching harmful radicals [27]. Albumin is also known to enter extra-vascular spaces in order to attract fluid in order to initiate the healing process [28]. Albumin also may be sequestered in areas where there is an inflammatory reaction as a protective coat to prevent further degradation of cellular materials, and hence blood albumin may be down regulated [29].

In this investigation, we clearly observe an acute inflammatory process occurring following BromAc administration, supported by the presence of low-grade fever in about one third of patients [13]. Since bromelain consists of several enzymes such as proteases, peroxidases, phosphatases, esterases, glycosylases, cellulases etc., it is capable of exerting enzymic reaction on a variety of compounds including proteins and glycoproteins [30], thereby changing their molecular features. On the other hand, acetylcysteine exerts its action on disulphide bonds, and hence also changes the configuration of protein and other biological molecules containing disulphide bonds [31]. Individually, they have been shown to enhance the penetration of macromolecules and drugs through membranes and other cellular structures $[8,32]$. Hence, owing to their chemical properties, the exposure of peritoneal surfaces to bromelain and acetylcysteine may initiate a chemical reaction affecting the cells lining the peritoneum, as well as blood vessels leading to inflammation. Beyond this, BromAc administration may also inadvertently release the components of cancer cells that are usually found intracellularly, by disrupting necrotic cell membranes and the surrounding mucinous barrier through drug action. The release of intracellular constituents into extracellular space is known to be a potent endogenous inducer of inflammation [33]. Furthermore, the large peritoneal surface may also absorb substantial quantities of bromelain and acetylcysteine potentially leading to systemic activity although the concentrations observed have yet to be demonstrated to have any effect. Future research into these areas is indicated.

We divided patients into two groups based on dosage (high and low dose) for post-hoc analysis, in order to explore if there were any potential blood marker effects that were impacted by the dosage given (see Table 3). We noticed a consistent picture between the two treatment groups, although there were numerical differences between groups which were 
Table 4 Blood biomarkers in high dosage patients (>100 mg bromelain)
Table 5 Coagulation parameters across low and high dosages

\begin{tabular}{|c|c|c|c|c|c|}
\hline Parameter & Units & Baseline (mean $\pm S D)$ & $\begin{array}{l}\text { Post-treatment } \\
(\text { mean } \pm \text { SD) }\end{array}$ & $p$-value & $\mathrm{n}$ \\
\hline Sodium & $\mathrm{mmol} / \mathrm{L}$ & $140.38 \pm 2.8$ & $139.25 \pm 3.34$ & 0.21 & 16 \\
\hline Potassium & $\mathrm{mmol} / \mathrm{L}$ & $4.41 \pm 0.59$ & $4.48 \pm 0.51$ & 0.68 & 16 \\
\hline Chloride & $\mathrm{mmol} / \mathrm{L}$ & $101.93 \pm 2.96$ & $99.5 \pm 4.4$ & 0.004 & 15 \\
\hline Bicarbonate & $\mathrm{mmol} / \mathrm{L}$ & $37.06 \pm 52.95$ & $26.88 \pm 2.19$ & 0.27 & 16 \\
\hline Urea & $\mathrm{mmol} / \mathrm{L}$ & $5.99 \pm 2.19$ & $5.97 \pm 2.72$ & 0.54 & 15 \\
\hline Creatinine & $\mu \mathrm{mol} / \mathrm{L}$ & $76.25 \pm 23.43$ & $80.87 \pm 18.93$ & 0.24 & 15 \\
\hline Total bilirubin & $\mu \mathrm{mol} / \mathrm{L}$ & $8 \pm 4.55$ & $11.31 \pm 14.1$ & 0.85 & 16 \\
\hline Total protein & $g / L$ & $68.33 \pm 10.93$ & $65.75 \pm 7.17$ & 0.26 & 15 \\
\hline Albumin & $g / L$ & $29.31 \pm 7.25$ & $24.31 \pm 5.67$ & 0.06 & 16 \\
\hline CRP & $\mathrm{mg} / \mathrm{L}$ & $48.93 \pm 51.81$ & $146.4 \pm 103.3$ & 0.009 & 14 \\
\hline ALP & $\mathrm{U} / \mathrm{L}$ & $154.63 \pm 115.22$ & $176.56 \pm 119.12$ & 0.87 & 16 \\
\hline GGT & $U / L$ & $73.6 \pm 75.45$ & $91.63 \pm 71.78$ & 0.45 & 15 \\
\hline ALT & $\mathrm{U} / \mathrm{L}$ & $25 \pm 9.36$ & $27.19 \pm 17.6$ & 0.84 & 16 \\
\hline AST & $\mathrm{U} / \mathrm{L}$ & $24.27 \pm 6.11$ & $28.13 \pm 23.94$ & 0.75 & 15 \\
\hline Haemoglobin & $10^{9} / \mathrm{L}$ & $107.19 \pm 27.49$ & $105.63 \pm 20.74$ & 0.61 & 16 \\
\hline WCC & $10^{9} / \mathrm{L}$ & $9.84 \pm 4.01$ & $11.52 \pm 3.17$ & 0.02 & 16 \\
\hline Neutrophils & $10^{9} / \mathrm{L}$ & $6.85 \pm 3.7$ & $8.44 \pm 2.62$ & 0.05 & 15 \\
\hline Lymphocytes & $10^{9} / \mathrm{L}$ & $1.88 \pm 0.95$ & $1.49 \pm 0.75$ & 0.05 & 15 \\
\hline Monocytes & $10^{9} / \mathrm{L}$ & $0.88 \pm 0.35$ & $1.11 \pm 0.57$ & 0.05 & 15 \\
\hline Eosinophils & $10^{9} / \mathrm{L}$ & $0.19 \pm 0.17$ & $0.2 \pm 0.19$ & 0.99 & 14 \\
\hline Basophils & $10^{9} / \mathrm{L}$ & $0.04 \pm 0.03$ & $0.03 \pm 0.02$ & 0.6 & 14 \\
\hline Platelets & $10^{9} / \mathrm{L}$ & $473.38 \pm 188.71$ & $601.33 \pm 263.29$ & 0.25 & 15 \\
\hline INR & INR & $1.26 \pm 0.36$ & $1.19 \pm 0.13$ & 0.63 & 14 \\
\hline APTT & s & $37.79 \pm 19.69$ & $35.5 \pm 11.84$ & 0.92 & 14 \\
\hline
\end{tabular}

ALP alkaline phosphatase, ALT alanine transaminase, APTT activated partial thromboplastin time, AST aspartate transaminase, CRP C-reactive protein, GGT gamma glutamyl transpeptidase, INR international normalized ratio, SD standard deviation, WCC white cell count

\begin{tabular}{lllll}
\hline & Parameter & $\begin{array}{l}\text { Pre-treatment } \\
(\text { mean } \pm \text { SD) }\end{array}$ & $\begin{array}{l}\text { Post-treatment } \\
(\text { mean } \pm \text { SD) }\end{array}$ & P-value \\
\hline All patients & INR & $1.2 \pm 0.3$ & $1.3 \pm 0.4$ & 0.73 \\
& APTT (s) & $35 \pm 14$ & $34 \pm 9$ & 0.60 \\
Low dose & INR & $1.2 \pm 0.4$ & $1.3 \pm 0.6$ & 0.58 \\
High dose & APTT (s) & $32 \pm 6$ & $33 \pm 6.5$ & 0.53 \\
& INR & $1.3 \pm 0.3$ & $1.2 \pm 0.1$ & 0.63 \\
\hline
\end{tabular}

APTT activated partial thromboplastin time, INR international normalised ratio, SD standard deviation

Table 6 Blood serum level of bromelain at $2-5 \mathrm{~h}$ after initial treatment

\begin{tabular}{|c|c|c|c|c|c|c|c|}
\hline \multirow[t]{2}{*}{ Route } & \multicolumn{4}{|c|}{ Drug administration } & \multicolumn{3}{|c|}{$\begin{array}{l}\text { Blood bromelain concen- } \\
\text { tration }(\mathrm{ng} / \mathrm{mL})\end{array}$} \\
\hline & Brom (mg) & $A c(g)$ & Volume $(\mathrm{mL})$ & $\begin{array}{l}\text { Brom conc. } \\
(\mathrm{mg} / \mathrm{mL})\end{array}$ & $2 \mathrm{~h}$ & $3 \mathrm{~h}$ & $5 \mathrm{~h}$ \\
\hline IT & 30 & 1.0 & 20 & 1.5 & - & 110 & - \\
\hline IP & 30 & 1.5 & 40 & 0.75 & 440 & - & 350 \\
\hline
\end{tabular}

Brom bromelain, Ac acetylcysteine, volume delivery volume, IT intra-tumoral administration, IP intraperitoneal administration 
difficult to interpret and inconsistent. Importantly, there could be a component of variation caused by the fact that high dose patients would have had a longer time elapse since their first dose of BromAc because of longer treatment time as they had more disease, confounding any interpretation of more acute parameters. Nevertheless, albumin appeared to be more significantly depressed in higher dosage patients potentially indicating a higher degree of inflammation. White blood cell and neutrophil concentration was increased by a proportionally higher amount in the low dose compared to the high dose group, although we note that the low dose group had a lower baseline to begin with because they are generally less ill patients (lower disease volume). Besides the identified differences in the length of treatment time, and drug dosage, differences in the low dose and the high dose groups may also be partly due to age differences, sex and other factors, in addition to their differences in the cancer stage. Most of the inflammatory markers are known to be affected, either down-regulated or up-regulated in cancer patients depending on the cancer stage [34]. Overall, we are unable to make any firm conclusions about dose related impacts of BromAc at the range of doses tested, as both high and low dose groups result in a reasonably consistent pattern of blood marker modulation when accounting for the variability of the dosages given.

We supplemented our investigation with an examination of blood bromelain concentrations in two patients, who had the same dosage of bromelain administered albeit with different delivery volumes and modes of delivery. Intraperitoneal delivery resulted in a much higher bromelain level of $440 \mathrm{ng} / \mathrm{mL}$ at $2 \mathrm{~h}$ as opposed to intra-tumoral delivery of $110 \mathrm{ng} / \mathrm{mL}$ at $3 \mathrm{~h}$. Intra-tumoral delivery of bromelain relies on diffusion out of the mucinous tumour before penetrating the peritoneal membrane and it is slower compared to direct IP delivery where vast peritoneal surfaces are exposed to bromelain immediately. Although the concentration of bromelain in IT delivery was $1.5 \mathrm{mg} / \mathrm{mL}$ as opposed to IP of $0.75 \mathrm{mg} / \mathrm{mL}$, the higher solution may have further enhanced absorption. Further the slightly higher acetylcysteine level of extra $0.5 \mathrm{~g}$ in IP delivery may have also influenced the penetration of bromelain. Bromelain has a high molecular weight $(28,000$ Daltons) and acetylcysteine may enhance the penetration of bromelain. Again, further study is required to clarify these preliminary hypotheses. Further pharmacokinetic analysis would be useful as it could support further development of BromAc administration through other routes of administration.

\section{Conclusion}

Intraperitoneal treatment using BromAc resulted in blood parameter derangements suggestive of an acute inflammatory response. There were no significant derangements to any other blood parameters noted, including liver enzymes or coagulation parameters.

Authors' contributions Conceptualization: SJV, JA, KP, and DLM; methodology: SB, KP, and JA; validation: KK, JA. KP, SB, and AHM; main manuscript writing and editing: KK, AHM and KP; figures and table preparation: KK, AHM and KP; ethics application SJV, and DLM; patient treatment SJV and DLM; supervision: DLM; funding acquisition: SJV, and DLM. All authors reviewed the manuscript. All authors read and approved the final manuscript.

Funding This research is partly funded by Mucpharm Pty Ltd, Australia.

Data availability The datasets generated during and/or analysed during the current study are available from the corresponding author on reasonable request.

\section{Declarations}

Competing interests DLM is the co-inventor and assignee of the Licence for this study and director of the spin-off sponsor company, Mucpharm Pty Ltd. KK, KP, AHM, JA and are employees of Mucpharm Pty Ltd. SJV is partly employed by Mucpharm for its cancer development and is supported by an Australian Government Research Training Program Scholarship.

Open Access This article is licensed under a Creative Commons Attribution 4.0 International License, which permits use, sharing, adaptation, distribution and reproduction in any medium or format, as long as you give appropriate credit to the original author(s) and the source, provide a link to the Creative Commons licence, and indicate if changes were made. The images or other third party material in this article are included in the article's Creative Commons licence, unless indicated otherwise in a credit line to the material. If material is not included in the article's Creative Commons licence and your intended use is not permitted by statutory regulation or exceeds the permitted use, you will need to obtain permission directly from the copyright holder. To view a copy of this licence, visit http://creativecommons.org/licenses/by/4.0/. 


\section{References}

1. Patrick-Brown T, et al. Estimating the prevalence of pseudomyxoma peritonei in Europe using a novel statistical method. Ann Surg Oncol. 2021;28(1):252-7.

2. Kusamura $S$, et al. The role of hyperthermic intraperitoneal chemotherapy in pseudomyxoma peritonei after cytoreductive surgery. JAMA Surg. 2021;156(3):e206363.

3. Delhorme JB, et al. Long-term survival after aggressive treatment of relapsed serosal or distant pseudomyxoma peritonei. Eur J Surg Oncol. 2017;43(1):159-67.

4. Lord AC, et al. Recurrence and outcome after complete tumour removal and hyperthermic intraperitoneal chemotherapy in 512 patients with pseudomyxoma peritonei from perforated appendiceal mucinous tumours. Eur J Surg Oncol. 2015;41(3):396-9.

5. Mercier F, et al. Recurrence of pseudomyxoma peritonei after cytoreductive surgery and hyperthermic intraperitoneal chemotherapy. BJS Open. 2019;3(2):195-202.

6. Chua TC, et al. Iterative cytoreductive surgery and hyperthermic intraperitoneal chemotherapy for recurrent peritoneal metastases. J Surg Oncol. 2013;108(2):81-8.

7. Dilly AK, et al. Improved chemosensitivity following mucolytic therapy in patient-derived models of mucinous appendix cancer. Transl Res. 2021;229:100-14.

8. Pavan R, et al. Properties and therapeutic application of bromelain: a review. Biotechnol Res Int. 2012;2012:976203.

9. Waring WS. Novel acetylcysteine regimens for treatment of paracetamol overdose. Ther Adv Drug Saf. 2012;3(6):305-15.

10. Stafanger G, Koch C. N-Acetylcysteine in cystic fibrosis and Pseudomonas aeruginosa infection: clinical score, spirometry and ciliary motility. Eur Respir J. 1989;2(3):234-7.

11. Dekhuijzen PN, van Beurden WJ. The role for $N$-acetylcysteine in the management of COPD. Int J Chron Obstruct Pulmon Dis. 2006;1(2):99-106.

12. Pillai K, Akhter J, Morris DL. Assessment of a novel mucolytic solution for dissolving mucus in pseudomyxoma peritonei: an ex vivo and in vitro study. Pleura Peritoneum. 2017;2(2):111-7.

13. Valle SJ, et al. A novel treatment of bromelain and acetylcysteine (BromAc) in patients with peritoneal mucinous tumours: a phase I first in man study. Eur J Surg Oncol. 2021;47(1):115-22.

14. Hosoda $\mathrm{H}$, et al. A comparison of chromogenic substrates for horseradish peroxidase as a label in steroid enzyme immunoassay. Chem Pharm Bull. 1986;34(10):4177-82.

15. Tochi BN, et al. Therapeutic application of pineapple protease (bromelain): a review. Pak J Nutr. 2008;7(4):513-20.

16. Suffredini AF, et al. New insights into the biology of the acute phase response. J Clin Immunol. 1999;19(4):203-14.

17. Fest $\mathrm{J}$, et al. Reference values for white blood-cell-based inflammatory markers in the Rotterdam study: a population-based prospective cohort study. Sci Rep. 2018;8(1):10566.

18. George EL, Panos AJN. Does a high WBC count signal infection? Nursing. 2005;35(1):20-1.

19. Taussig SJ, Batkin S. Bromelain, the enzyme complex of pineapple (Ananas comosus) and its clinical application. An update. J Ethnopharmacol. 1988;22(2):191-203.

20. Kaur $\mathrm{H}$, et al. Bromelain has paradoxical effects on blood coagulability: a study using thromboelastography. Blood Coagul Fibrinolysis. 2016;27(7):745-52.

21. Sahbaz A, et al. Bromelain: a natural proteolytic for intra-abdominal adhesion prevention. Int J Surg. 2015;14:7-11.

22. Forget $P$, et al. What is the normal value of the neutrophil-to-lymphocyte ratio? BMC Res Notes. 2017;10(1):1-4.

23. Turkmen $\mathrm{K}$, et al. Platelet-to-lymphocyte ratio better predicts inflammation than neutrophil-to-lymphocyte ratio in end-stage renal disease patients. Hemodial Int. 2013:17(3):391-6.

24. Soeters PB, Wolfe RR, Shenkin A. Hypoalbuminemia: pathogenesis and clinical significance. JPEN J Parenter Enteral Nutr. 2019;43(2):181-93.

25. Meloun B, Moravek L, Kostka V. Complete amino acid sequence of human serum albumin. FEBS Lett. 1975;58(1):134-7.

26. Bocedi $A$, et al. Thiol disulfide exchange reactions in human serum albumin: the apparent paradox of the redox transitions of Cys34. FEBS J. 2018;285(17):3225-37.

27. Taverna M, et al. Specific antioxidant properties of human serum albumin. Ann Intensive Care. 2013;3(1):4.

28. Kobayashi $\mathrm{N}$, et al. The early influence of albumin administration on protein metabolism and wound healing in burned rats. Wound Repair Regen. 2004;12(1):109-14.

29. Quinlan GJ, Martin GS, Evans TW. Albumin: biochemical properties and therapeutic potential. Hepatology. 2005;41(6):1211-9.

30. Putriana $L$, et al. The effect of bromelain from pineapple (Ananas comosus) on increasing protein digestibility of milk replacer for lamb. In: IOP conference series: earth and environmental science. IOP Publishing; 2020.

31. Aldini G, et al. N-Acetylcysteine as an antioxidant and disulphide breaking agent: the reasons why. Free Radic Res. 2018;52(7):751-62.

32. Zhang $\mathrm{S}$, et al. The enhancement of $\mathrm{N}$-acetylcysteine on intestinal absorption and oral bioavailability of hydrophobic curcumin. Eur $\mathrm{J}$ Pharm Sci. 2020;154:105506.

33. Beg AA. Endogenous ligands of Toll-like receptors: implications for regulating inflammatory and immune responses. Trends Immunol. 2002;23(11):509-12.

34. II'yasova D, et al. Circulating levels of inflammatory markers and cancer risk in the health aging and body composition cohort. Cancer Epidemiol Biomark Prev. 2005;14(10):2413-8.

Publisher's Note Springer Nature remains neutral with regard to jurisdictional claims in published maps and institutional affiliations. 